\title{
A ESCRITA DO ESTILO
}

\section{Elisabeth Bittencourt ${ }^{(*)}$}

É preciso ser mais forte do que si mesmo para abordar a escrita. É uma coisa gozada, sim. Não é apenas a escrita, o escrito, é o grito das feras noturnas, de todos, de você e eu, os gritos dos cães (DURAS, 1994, p.23).

O estilo é o que se espera na produção de um analista? Ou melhor, o estilo traria uma certa possibilidade a esse lugar impossível que é o de analista? Uma possibilidade para o ser sustentar seu desser? Nisso, ele seria produto deste lugar de hiância?

Se então a produção de um estilo é o que se pode esperar na formação do analista, este tem na autorização de si-mesmo seu suporte fundamental. E essa produção é efeito de uma análise pessoal trabalho de transferência - e de sua transferência com o estilo da teoria da psicanálise, constituída radicalmente pela falta de objeto.

Qual seria a prova material de que Isso existe? No entanto, existe. Se existe é porque há uma práxis, um discurso sendo sustentado... por quem? Por analistas, é claro.

E mais, além destes, há seres outros que se engajam nessa aventura de dizer o nada a dizer. Parceiros nessa crença, podemos dizer, então, que a Psicanálise anda, caminha e deixa cada vez mais pegadas. Restos de significantes, ecos de homofonia, letras que, por sua omissão ou tropeço, apontaram um outro sentido que não pára-denão-se-inscrever.

Sim, mas e o estilo de um analista? De que se trata?

\section{O OBJETO A: EIXO TEÓRICO NA CONSTTRUÇÃO DE UM ESTILO}

Se o estilo tem sua referência na ordem objetal - construção de um certo modo de engendrar -, significa que sua construção está na ordem da causa do desejo. Ou seja, da falta, objeto a, podendo entrar no jogo simbólico da transferência e nela se recortar. É nesse recorte,

(") Psicanalista e escritora, São Luís/MA. 
por uma fantasia, que atravessa o percurso de uma análise, que o estilo de um analista vai se construindo.

A formação do estilo de um analista dependeria, então, de alguns fatores. É efeito de uma análise, produção de S1 e do desejo de analista que busca construir uma autorização para que aquele, enquanto praticante do simbólico, encontre uma via de possibilidade para a psicanálise se presentificar.

Como construir um estilo, um certo modo de fazer aquele sujeitinho ali vomitar suas palavras, num espasmo, ou seja, sem pensar? Como cobrar faltas e ainda dizer que aquele dia, se ele não veio, se foi justo ou não, isso não importa, importando apenas como posso disso me aproveitar para promover um furo no discurso e daí advir alguma significação?

Enfim, como criar um estilo que tenha no desarrazoado da ética do desejo sua medida? A via que se apresenta é a da autorização. A partir daí, um analista, depois de ter esquecido a teoria, torna-se um Outro de si mesmo e, por causa disso, já não é ele, é esse outro que lá trabalha à sua revelia, conforme sua posição de morto: o seu ser não conta. Mas que ser é esse?

\section{ENTRADA EM ANÁLISE}

Apesar de o sujeito suposto saber ser o que serve de suporte para o início de uma análise, o desejo de ser analista já está latente para esse que demanda uma análise?

O certo é que esse que demanda uma análise aposta num possível desvelamento de sua fantasia insensata, aquela que o incitou a trilhar por esses caminhos de viés que a Psicanálise indica, ética do desejo. Uma espécie de engajamento numa canoa furada, mas que, apesar disso, não soçobra; pelo contrário, leva adiante, acha a realidade da cadeia significante que revele o sujeito desse ser esperançoso de se desvelar, desvelo não-todo, mas desvelo.

É nessa aposta insensata que este ser se engaja até o tempo em que no percurso de sua análise - trabalho de transferência - revele sua transferência de trabalho, essa que serve de suporte na articulação do desejo com a escrita, efeito da alíngua que num golpe só revela o inconsciente e suas formações. 
Mas se o estilo de um analista é feito de um autorizar-se, este vai precisar inventar-se. Para tal, é preciso que arranje uma espécie de aval que vem da burilação do desejo de analista e da transferência de trabalho. Afinidades com a teoria, para ir adiante na invenção desse saber particular.

É num só-depois que uma autorização surge, justo porque ele não pode planejar seu ato. Este é efeito de passagem de risco, ou melhor, transferência com a teoria e a ética da psicanálise.

Isso que é invenção de um analista - seu estilo - traz uma marca pessoal e portanto uma autoria, que vai se engendrar na autorização, enquanto uma via singular de inscrição do saber da psicanálise. E este sabemos que é não-todo.

Sendo assim, o estilo de saber que a psicanálise apresenta cria transferência, transferência com o texto, ou seja, transferência com o modo de funcionamento e estrutura da teoria que é feito de certas condições. Sua estrutura é faltosa, menos-um, que engendra pela via significante Outras promessas de significação.

É porque há um a-menos na cadeia significante, é porque falta um à alíngua, que pode haver possibilidade de articulação. É porque há algo que fecha, mas que ao mesmo tempo é esburacado, que o deslizamento dos significantes é possível, conforme cada sujeito, como os analistas, um a um.

O saber da psicanálise é não-todo, faz parte do campo da particularidade, depende de um ser que o suporte. Esse não-todo criaria um certo estilo na relação com o saber? O estilo de um analista, então, seria também efeito de criação dessa transferência que o campo do não-todo provoca?

Sim, porque há analistas, ou seja, seres que fazem uma inscrição particular nesse saber furado que a psicanálise apresenta. A prova de sua existência está na escrita, eles se escrevem a partir da alíngua e se presentificam por aí. As provas são muitas, textos e mais textos, sessões clínicas, articulações com outros campos. Se não há realidade pré-discursiva, o discurso cria existência se presentificando na escrita, escrita de um estilo?

A escrita, ao contrário da psicanálise, é transmissível, sustenta articulações que esticam o limite do sentido. A letra se descola, cai e 
abre uma outra cena que é a que nos interessa, o significante operando na linguagem.

\section{A ESCRITA}

E o que é uma escrita? Escrita é sempre escrita, ou seja, letras articuladas, unidades em si vazias de sentido, mas passíveis de se articularem a outras e daí advir sentido. Agora, uma escrita do limite da escrita se interessa pelo que é apenas efeito de linguagem, prova do fato de haver inconsciente.

O que a escrita quer é buscar suportes para que a Lei do significante se realize, comandando a função da significância. Escrita do inconsciente que realiza o milagre de uma impossibilidade sustentar-se apenas como efeito do significante. Um lugar de possibilidade da escrita de algo que escapa ao sentido.

Trata-se, então, de uma escrita fundada pelo que funciona como campo da fala e que se constitui enquanto efeito de discurso, conforme diz Lacan no Seminário 20. "A condição da escrita é ser sustentada por um discurso cuja significação escapa"1, mas é suportada pela teoria da psicanálise.

Um campo de escrita da fala do Outro articulada apenas pela condição da linguagem e pela barra. Ponto a partir do qual se insemina a produção do escrito representativo do lugar que o sujeito ocupa perante o saber, campo do Outro, o de barrado. Lacan destaca essa barra: sem ela, a virulência fértil do significante, que contamina o significado, perderia sua potência, não sendo possível a quebra de uma suposta "naturalidade" que o ato da fala sempre aparentou ter.

\section{O ESTILO E A TRANSFERÊENCIA DE TRABALHO}

O lugar particular que um sujeito ocupa perante o saber da psicanálise - transferência de trabalho - engendra o estilo de um analista? Construção da fantasia particular do sujeito em sua referência ao Outro, enquanto desejo de analista?

LACAN, Jacques. O seminário: mais, ainda... Tradução de M. D. Magno. Rio de Janeiro: Jorge Zahar, 1985. 
O estilo de um analista seria então inventado de si-mesmo e presentificado pela escrita que sustenta um lugar de impossibilidade. Pura dependência da cadeia significante.

Se o sujeito se inventa, torna-se o autor de si-mesmo. Sua prova material - formação de analista - se sustenta pela via da escrita que o conta, o realiza, o tira da ordem do não-realizado, dá existência. Invenção que é feita após uma desconstrução. Recusa da sintaxe, preferência pela letra, passagem da literatura para a escritura. Dissolução de imagens, letra que se destaca e se faz escrito; o estilo de um analista é apenas uma de suas possibilidades.

A escrita quer dizer das coisas do inconsciente, atualizar a psicopatologia do cotidiano, escrever o estilo de um analista que em sua direta articulação com o autorizar-se, não-pára-de-não-seinscrever, presentificando o real da formação do analista. Quer ir além do que parecia um ponto de limite pela via da escritura, único recurso possível para esse termo, visto que aqui o que podemos testemunhar é um liame com aquilo que é da ordem da falta se escrevendo.

\section{A ESCRITA DO ESTILO DE MARGUERITE DURAS}

Já me encaminhando para o fim desse trabalho, me servirei de Marguerite Duras. Presentificar aqui entre nós, essa que morreu este ano comemorando aquilo que é da zona que Lacan nomeou como entre-duas-mortes na qual, conforme ele: "o olhar se transforma em beleza, já o descrevi", ele diz na homenagem que faz a Marguerite: "é o limiar entre duas mortes: o belo"2. Ou seja, comemoração que se realiza pela morte, por uma passagem.

Sua escrita se faz de falhas, brancos, como diz Marguerite: "... eu the digo como acontecem, são brancos que aparecem, talvez em virtude de uma recusa violenta da sintaxe, sim, acho que sim, reconheço alguma coisa nisso" ${ }^{3}$. Ela faz Lacan lembrar para todos aqueles que querem ver o artista pela via de sua neurose, que Freud disse que estes sempre foram os precursores. Que Marguerite escreve

2 LACAN, Jacques. Homenagem a Marguerite Duras. Tradução de Eunice Martinho. Lisboa: Assírio e Alvim, 1989, p.129

3 DURAS, Marguerite. Boas falas:conversas sem compromisso. Tradução de Sieni Maria Campos. Rio de Janeiro: Record, 1974, p.11. 
seu ensino: "Que a prática da letra converge com o uso do inconsciente é tudo que testemunharei, rendendo-lhe homenagem"4.

Marguerite é prova do liame da autoria com a estrutura faltosa, sustentando uma experiência "que deixa acontecer", como ela diz, "dolorosa de escrever, de ler", e acrescenta: "dolorosa porque é um trabalho relativo a uma região... ainda não explorada talvez"15. Escrita que privilegia a dissolução de imagens, uma temporalidade outra com acontecimentos que exigem alguma coisa da ordem da experiência: " Eu experimentava esse branco na seqüência" ${ }^{6}$.

Passar pela experiência, colocando no cenário a inauguração de Freud: a Psicanálise, reinventando-a. Experiência ousada que lembra a experiência analítica quando, pela operação do recalque, o sujeito não pode ir adiante, fica ali pregado. Não passa. Passando pela experiência da análise há a promessa vaga de que a letra do sintoma se destaque, se escreva e ele possa ir adiante.

Marguerite diz não ter tido escolha: "Eu escrevia como quem vai ao escritório, todos os dias, tranqüilamente. Levava alguns meses para fazer um livro e então, de repente, veio a virada"7. Mas será? Sua escolha - Desejo de desejo - não foi pela falta? Ou seja, pelo saber da Psicanálise que comemora o campo do não-todo, - efeito de transferência com a teoria? Afinal, sua escrita ilumina estranhamente seus textos, seu perigo é abismal: "Em minha sombra interna onde a fomentação do eu por mim se faz, em minha região escrita, eu leio que aconteceu aquilo" ${ }^{8}$.

Não seria ela amante disso que manca no simbólico? Falha constitutiva que a joga nas mãos de um destino traçado à revelia? Experiência freudiana em que a verdade é aquilo que aparece pelo falho, pelo sintoma, produzindo assim articulações do inconsciente e do campo do real, que pela via de um escorregão de sentido mostra um outro? "Não me importo jamais com o sentido, a significação. Se há sentido, este desprende-se depois"?

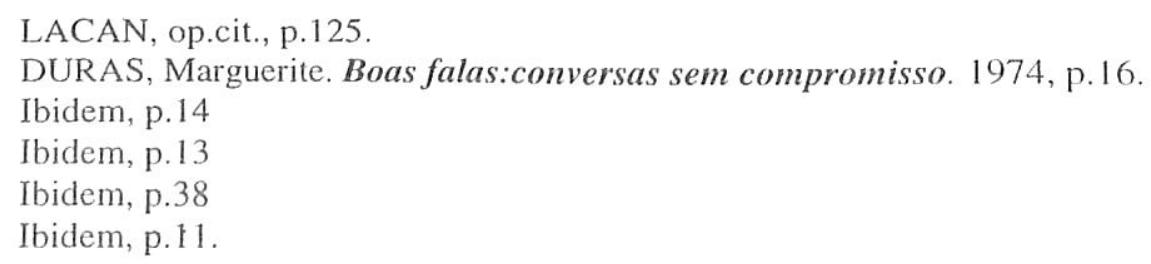


Assim, aproveito este momento não só para homenagear Marguerite, mas ainda para dizer que a escrita é uma estrutura capaz de sustentar e transmitir aquilo que é da ordem do estilo de um analista. Lugar de possibilidade em uma clínica. Esta, contudo, não se restringe àquilo que da autorização cria uma possibilidade para a invenção da Psicanálise.

Podemos pensar também que se não há um ideal de cura, há final de análise. O estilo seria então uma possibilidade para este ser faltoso, que por falar, se perde nos meandros do labirinto do seu tornar-se. O estilo seria, então, uma via para esse que vai precisar subjetivar-se para saber, não sabendo, das suas vias próprias de gozo?

Termino com palavras de Marguerite: "Meus livros saíram desta casa. Desta luz também, do parque. Desta luz que reverbera no tanque. Precisei de vinte anos para escrever isso que acabei de dizer"10.

\section{REFERÊNCIAS BIBLIOGRÁFICAS}

LACAN, Jacques. Homenagem a Marguerite Duras. Tradução de Eunice Martinho. Lisboa: Assírio e Alvim, 1989.

LACAN, Jacques. O seminário: mais, ainda... Tradução de M. D. Magno. Rio de Janeiro: Jorge Zahar, 1985.

DURAS, Marguerite. Boas falas: conversas sem compromisso. Tradução de Sieni Maria Campos. Rio de Janeiro: Record, 1974.

DURAS, Marguerite. Escrever. Tradução de Rubens Figueiredo. Rio de Janeiro: Rocco, 1994.

10 DURAS, Marguerite. Escrever. Tradução de Rubens Figueiredo. Rio de Janeiro: Rocco, 1994, p.16. 